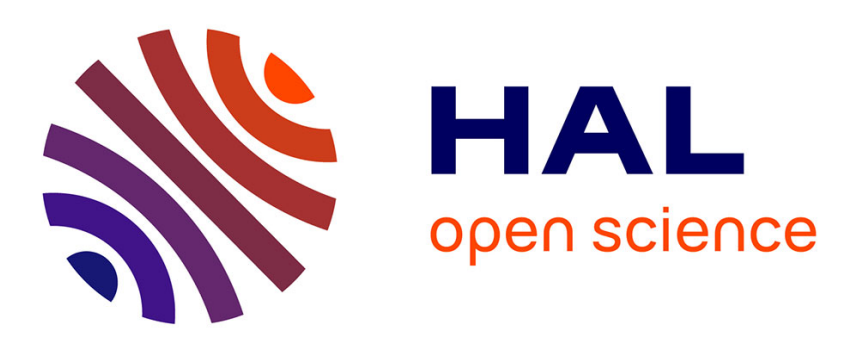

\title{
Nanoindentation of $\mathrm{NiAl}$ and Ni3Al crystals on (100), (110), and (111) surfaces: A molecular dynamics study Richard Seymour, Anne Hémeryck, Ken-Ichi K Nomura, Weiqiang Wang, Rajiv K Kalia, Aiichiro Nakano, Priya Vashishta
}

\section{- To cite this version:}

Richard Seymour, Anne Hémeryck, Ken-Ichi K Nomura, Weiqiang Wang, Rajiv K Kalia, et al.. Nanoindentation of NiAl and Ni3Al crystals on (100), (110), and (111) surfaces: A molecular dynamics study. Applied Physics Letters, 2014, 104 (14), pp.141904 - 84907. 10.1063/1.4867168 . hal-01496618

\section{HAL Id: hal-01496618 \\ https://hal.laas.fr/hal-01496618}

Submitted on 27 Mar 2017

HAL is a multi-disciplinary open access archive for the deposit and dissemination of scientific research documents, whether they are published or not. The documents may come from teaching and research institutions in France or abroad, or from public or private research centers.
L'archive ouverte pluridisciplinaire HAL, est destinée au dépôt et à la diffusion de documents scientifiques de niveau recherche, publiés ou non, émanant des établissements d'enseignement et de recherche français ou étrangers, des laboratoires publics ou privés. 


\section{AIP Applied Physics \\ Letters}

Nanoindentation of NiAl and Ni3Al crystals on (100), (110), and (111) surfaces: A molecular dynamics study

Richard Seymour, Anne Hemeryck, Ken-ichi Nomura, Weiqiang Wang, Rajiv K. Kalia, Aiichiro Nakano, and Priya Vashishta

Citation: Applied Physics Letters 104, 141904 (2014); doi: 10.1063/1.4867168

View online: http://dx.doi.org/10.1063/1.4867168

View Table of Contents: http://scitation.aip.org/content/aip/journal/apl/104/14?ver=pdfcov

Published by the AIP Publishing

\section{Articles you may be interested in}

Molecular dynamics simulations of the melting curve of NiAl alloy under pressure

AIP Advances 4, 057110 (2014); 10.1063/1.4876515

Serrated flow behaviors of a Zr-based bulk metallic glass by nanoindentation

J. Appl. Phys. 115, 084907 (2014); 10.1063/1.4866874

Spherical nanoindentation study of the deformation micromechanisms of $\mathrm{LiTaO} 3$ single crystals

J. Appl. Phys. 110, 023516 (2011); 10.1063/1.3608158

Response to "Comment on 'Nanoindentation hardness anisotropy of alumina crystal: a molecular-dynamics study"' [Appl. Phys. Lett.94, 146101 (2009)]

Appl. Phys. Lett. 94, 146102 (2009); 10.1063/1.3114376

Comment on "Nanoindentation hardness anisotropy of alumina crystal: A molecular dynamics study" [Appl. Phys. Lett.92, 161904 (2008)]

Appl. Phys. Lett. 94, 146101 (2009); 10.1063/1.3114374

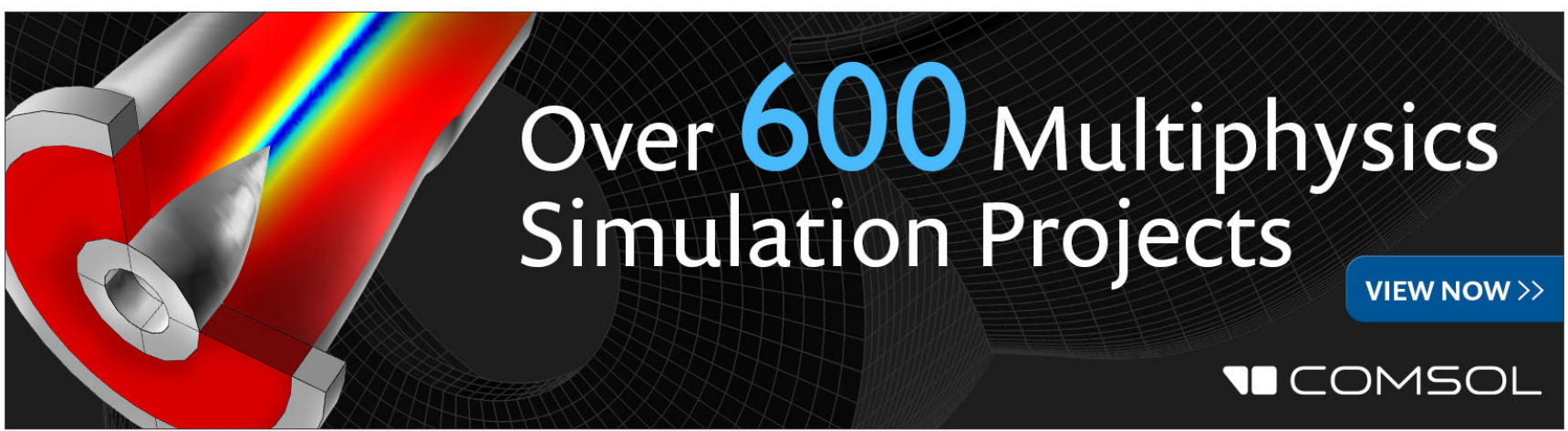




\title{
Nanoindentation of $\mathrm{NiAl}$ and $\mathrm{Ni}_{3} \mathrm{Al}$ crystals on (100), (110), and (111) surfaces: A molecular dynamics study
}

\author{
Richard Seymour, ${ }^{1}$ Anne Hemeryck, ${ }^{2,3}$ Ken-ichi Nomura, ${ }^{1}$ Weiqiang Wang, ${ }^{1}$ Rajiv K. Kalia, ${ }^{1}$ \\ Aiichiro Nakano, ${ }^{1}$ and Priya Vashishta ${ }^{1}$ \\ ${ }^{1}$ Collaboratory for Advanced Computing and Simulations, Department of Chemical Engineering \& Materials \\ Science, Department of Physics \& Astronomy, Department of Computer Science, University of Southern \\ California, Los Angeles, California 90089-0242, USA \\ ${ }^{2}$ CNRS, LAAS, 7 avenue du Colonel Roche, F-31400 Toulouse, France \\ ${ }^{3}$ Universite de Toulouse, LAAS, F-31400 Toulouse, France
}

(Received 28 October 2013; accepted 4 February 2014; published online 7 April 2014)

\begin{abstract}
Molecular dynamics simulations were performed to study the nanoindentation of $\mathrm{NiAl}$ and $\mathrm{Ni}_{3} \mathrm{Al}$ crystals on three surfaces: (100), (110), and (111). The calculated load-displacement curves show discrete drops at certain indentation depths, indicating dislocation bursts during indentation. The hardness values for the two materials were found to depend significantly on the indented crystallographic plane: the (100) surface is the softest for $\mathrm{NiAl}$ and the hardest for $\mathrm{Ni}_{3} \mathrm{Al}$. We also found distinctive deformation activities in the subsurface region in $\mathrm{Ni}_{3} \mathrm{Al}$ crystals, while dislocation loops propagate deep into the substrate in NiAl systems. (C) 2014 Author(s). All article content, except where otherwise noted, is licensed under a Creative Commons Attribution 3.0 Unported License. [http://dx.doi.org/10.1063/1.4867168]
\end{abstract}

Nickel aluminide is an intermetallic compound with important technological applications because of its light weight as well as its resistance to oxidation, corrosion, structural deformation, and yield strength at high temperatures. ${ }^{1-6}$ In intermetallic compounds, the coexistence of metallic and covalent interatomic bonding ${ }^{7,8}$ makes their mechanical properties highly nontrivial. An example is the anomalous yield strength of $\mathrm{Ni}_{3} \mathrm{Al}$ at elevated temperatures. Unlike ordinary materials, it exhibits maximum strength before melting, as the temperature increases. The strength of nickel aluminide also depends on crystallographic orientations. In transition metal alloys such as $\mathrm{NiAl}$, structural transformation is observed under applied stress. In the molecular dynamics (MD) simulation of nanowires carried out by Park, ${ }^{9}$ the strain response of $\mathrm{NiAl}$ was shown to change from brittle to super elastic via martensitic phase transformation. Zhang et al. suggested that in NiAl, dislocations can serve plastic accommodation during the growth of martensitic transformation..$^{10}$ Using transmission electron microscopy, Zhu et al. studied the orientation dependence of creep behavior in $\mathrm{Ni}_{3} \mathrm{Al}$ single crystal and observed a crossover of slip systems-from octahedral to cubic planes- between the primary and secondary creep stages. ${ }^{11}$ Kozlov et al. studied the anomalous temperature dependence of the yield point in $\mathrm{Ni}_{3} \mathrm{Al}$ and attributed it to the anisotropic atomic arrangement in dislocation glide planes. ${ }^{12}$ Though nickel aluminide compounds have been widely used in gas turbines and jet engines, their brittleness hinders their use as thin films in many engineering applications. ${ }^{1}$ One approach toward overcoming this difficulty may be through nanostructural design. In fact, unique mechanical properties have been observed experimentally for $\mathrm{Ni}_{3} \mathrm{Al}$ nanocubes ${ }^{6}$ and through $\mathrm{MD}$ simulations for $\mathrm{Ni}_{3} \mathrm{Al}$ nanowires. ${ }^{13}$ A key to controlling these nanomechanical properties is the atomistic understanding of anisotropic mechanical responses on different crystallographic surfaces.

Nanoindentation is a widely used experimental technique to examine the mechanical response of materials, including the slip system, through localized damage induced by a sharp indenter tip. ${ }^{14-18} \mathrm{~A}$ number of nano-to-micro indentation studies has been carried out on $\mathrm{NiAl}$ and $\mathrm{Ni}_{3} \mathrm{Al}$ single crystals, ${ }^{18-20}$ multilayered thin films, ${ }^{21} \mathrm{NiAl}$-coated $\mathrm{Ni}$ substrate, ${ }^{22}$ and other Ni alloys, ${ }^{23}$ which shows an indentation size effect and anisotropic hardness with respect to the indenter orientation. ${ }^{24-27} \mathrm{MD}$ simulations have been used to investigate atomistic processes during nanoindentation for metals and ceramics. ${ }^{28-30}$ Although extensive research has been done on nickel aluminide systems, a comprehensive study of their mechanical responses is still lacking. In this work, we have performed nanoindentation MD simulations on three nickel aluminide surfaces: (100), (110), and (111) for $\mathrm{B} 2-\mathrm{NiAl}$ and $\mathrm{L1}_{2}-\mathrm{Ni}_{3} \mathrm{Al}$ crystals.

Figures 1(a)-1(c) show the unit cell structure of B2 $\mathrm{NiAl}$ and $\mathrm{L}_{2} \mathrm{Ni}_{3} \mathrm{Al}$ crystals and a schematic of a nanoindentation simulations setup. We used an embedded atom method (EAM) type potential developed by Chen, Srolovitz, and Voter $^{31}$ to investigate the $\mathrm{NiAl}$ and $\mathrm{Ni}_{3} \mathrm{Al}$ systems. With EAM's interatomic potential, Chen et al. studied the grain boundary (GB) structure, GB cohesive energy, and stain distribution around GBs. To perform MD simulations of NiAl systems, we also examined the cohesive energy, bulk modulus, and surface energy of $\mathrm{B} 2-\mathrm{NiAl}$, which show reasonable agreement with the literature. The film dimensions for the six systems are approximately $180 \AA, 180 \AA$, and $170 \AA$ in the $\mathrm{x}-, \mathrm{y}-$, and $\mathrm{z}$ - directions, respectively. NiAl systems with the (100), (110), and (111) surfaces contain 450560, 560000 , and 476928 atoms. The numbers of atoms for $\mathrm{Ni}_{3} \mathrm{Al}$ crystals with the (100), (110), and (111) surfaces are 486 720, 492 544, and 471 744, respectively. Periodic boundary conditions are applied in the $\mathrm{x}$ - and $\mathrm{y}$ - directions perpendicular to the indentation direction. The thin film is initially quenched to $0 \mathrm{~K}$ to relax the surfaces and is gradually heated up and thermalized at $300 \mathrm{~K}$. A thin layer of atoms, $5 \AA$ from the bottom of the film in the z- direction, is fixed to hold the film during simulation. In all simulations, we use a 
(a)

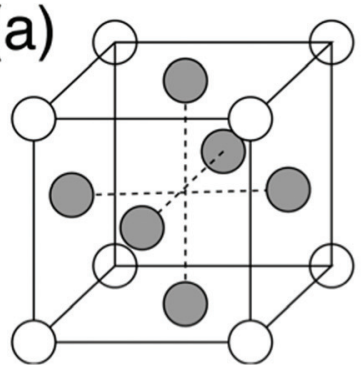

(b)

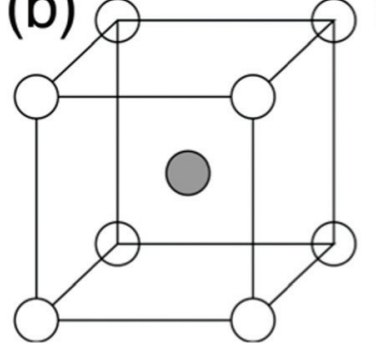

(c)

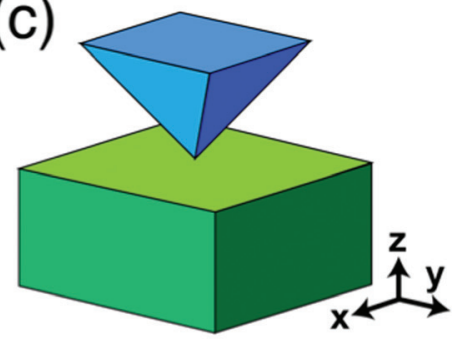

FIG. 1. (a) B2 NiAl crystalline unit cell and (b) $\mathrm{L}_{2} \mathrm{Ni}_{3} \mathrm{Al}$ crystalline unit cell, where gray and white circles represent $\mathrm{Ni}$ and $\mathrm{Al}$ atoms, respectively. (c) Schematic of nanoindentation simulation setup. Blue pyramidal shape and the green rectangle represent an indenter and a substrate, respectively. four-faced pyramidal-shape rigid indenter with a $90^{\circ}$ edge angle cut out of an fcc crystal. The indenter atoms interact with film atoms through pure repulsion. One MD time step is 2.5 fs throughout the simulations. During the loading phase, the indenter is moved into the film by $0.5 \AA$ for 1000 time steps. Subsequently, we relax the system by holding the indenter for 9000 time steps. We repeat this process until the total indentation depth reaches approximately one-quarter of the film thickness, corresponding to $40 \AA$ from top surface. During unloading phase, we use the same schedule except for reversing the direction of the indenter displacement. To indentify defect atoms, we used coordination number and common neighborhood parameter (CNP). ${ }^{32}$

Table I summarizes hardness values (i.e., the indenter load divided by the projected indentation area) obtained for the six simulations. In the $\mathrm{NiAl}$ systems, the (100) surface is notably softer than the (110) and (111) surfaces. On the other hand, the (100) surface is harder than the other two surfaces in the $\mathrm{Ni}_{3} \mathrm{Al}$ systems.

Figure 2 shows the load-displacement curves $(P-h)$ and hardness for the $\mathrm{NiAl}(100)$ and $\mathrm{Ni}_{3} \mathrm{Al}$ (100) systems. We observe several drops in the $P$ - $h$ curves during the loading phase (pop in) indicating discrete deformation events in our systems. The hardness values of the six systems exhibit the indentation size effect and crystallographic-orientation dependency.

Figure 3 below shows snapshots of the dislocation activities in NiAl (100) at the indentation depth $h=40 \AA$. During indentation, dislocations form a loop structure (pointed by the yellow arrow), which glides in the [100] direction moving away from the indenter. The loop develops into a skewed square shape ${ }^{33}$ with the sides oriented towards the [1 $\left.1 \overline{1} 2\right]$ and [112] directions (see Fig. 3(b)). At $h=40 \AA$, we also observe the nucleation of second dislocation loop (pointed by the red arrow).

Figure 4 shows the dislocation loop under the indenter with half of the top surface of the system cut away on the (011) plane. In the NiAl (110) and NiAl (111) simulations, two dislocation loops are formed one after the other, parallel to each other and separated by about $15 \AA{ }^{34}$ In contrast to the NiAl systems, dislocation activities are rather confined within the subsurface regions in the $\mathrm{Ni}_{3} \mathrm{Al}$ crystals. Figure

TABLE I. Hardness of $\mathrm{NiAl}$ and $\mathrm{Ni}_{3} \mathrm{Al}$ with the (100), (110), and (111) surfaces.

\begin{tabular}{llll}
\hline \hline Hardness (GPa) & $(100)$ & $(110)$ & $(111)$ \\
\hline $\mathrm{NiAl}$ & 11.9 & 16.9 & 17.0 \\
$\mathrm{Ni}_{3} \mathrm{Al}$ & 21.5 & 17.8 & 18.4 \\
\hline \hline
\end{tabular}
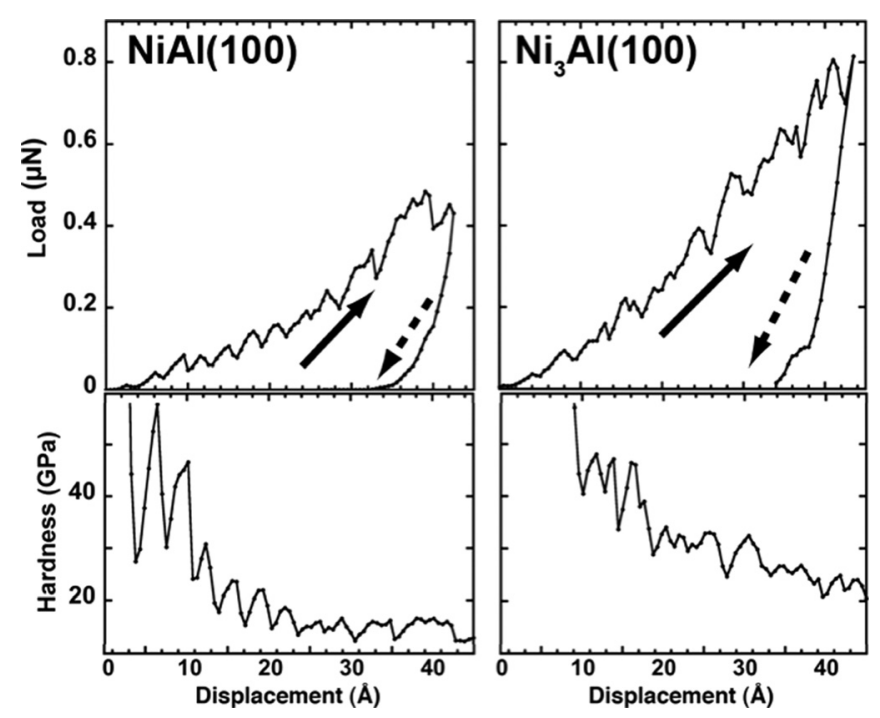

FIG. 2. (Left) Load-displacement curve and hardness of NiAl with the (100) surface. Solid and dashed arrows indicate the loading and unloading processes, respectively. (Right) Load-displacement curve and hardness of $\mathrm{Ni}_{3} \mathrm{Al}$ with the (100) surfaces.

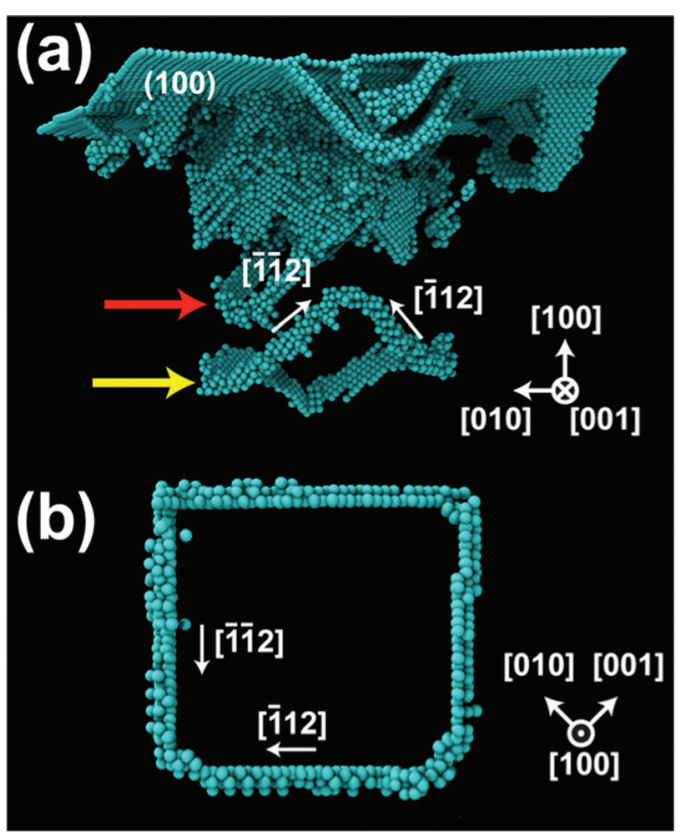

FIG. 3. (a) Snapshot of dislocation activity in NiAl (100) at indentation depth $h=40 \AA$ A. Defect atoms detected by coordination number are shown. The red arrow indicates a new dislocation loop that begins to form. (b) Topview of the "square-shape" dislocation loop (pointed by the yellow arrow in (a)) projected on the (100) plane. 


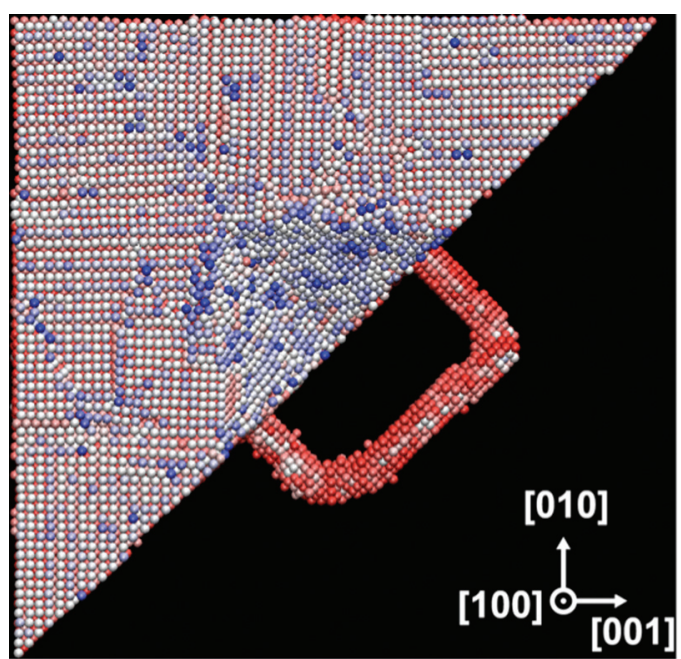

FIG. 4. The dislocation loop underneath the indenter in the NiAl (100) system. For clarity, indenter atoms are not shown. The defect atoms are indentified by their coordination number and colored by the common neighborhood parameter value.

5(a) displays a snapshot of dislocation activities near the indenter at the indentation depth $h=25 \AA$. By increasing indentation depth, dislocations nucleate from the corner of the indenter and develop into a V-shape that subsequently travels away from the indenter via edge dislocations on the $\{111\}$ family of planes. Figure 5(b) shows the distribution of surface atoms in the vicinity of the V-shape slip planes

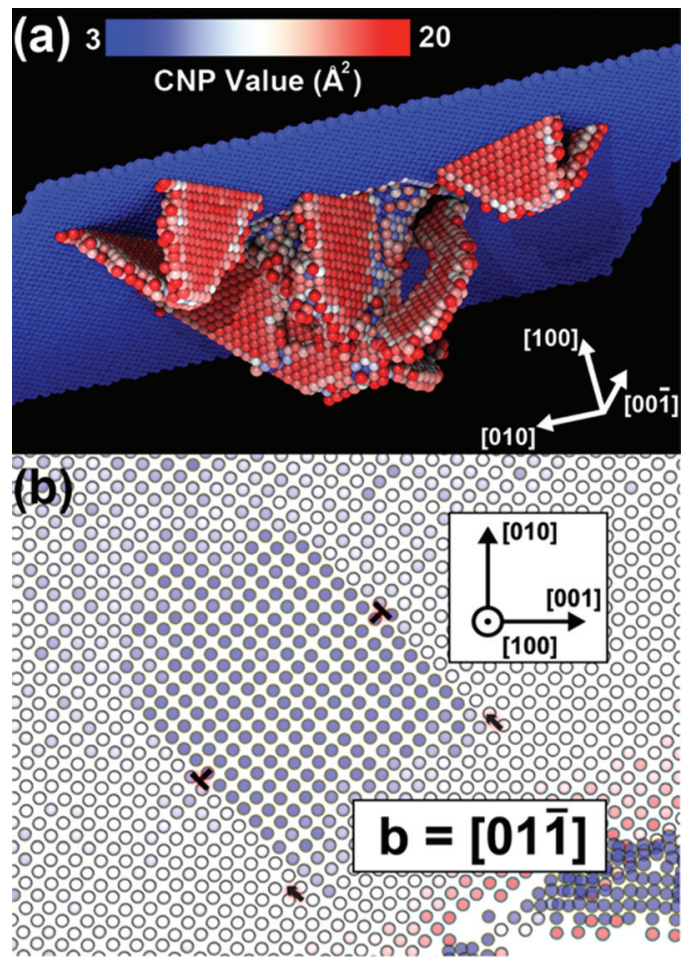

FIG. 5. (a) Nucleation and propagation of V-shape $\{111\}$ slip planes in $\mathrm{Ni}_{3} \mathrm{Al}(100)$ at indentation depth $h=25 \AA$. Atoms are color-coded by the common neighborhood parameter values. Atoms in the indenter and in the bulk condition are not shown for clarity. (b) Top view of the surface atoms configuration around the V-shape slip planes in $\mathrm{Ni}_{3} \mathrm{Al}$ (100). Circles show the position of the surface atoms that are color-coded by their relative coordinates in [100]. The T-marks indicate the position of the dislocations. The indenter is at right-bottom corner and not shown for clarity. looking down on the (100) plane. Burgers vector analysis shows that the two partial dislocations, $\frac{1}{6}\langle 11 \overline{2}\rangle$ and $\frac{1}{6}\langle\overline{1} 2 \overline{1}\rangle$, comprise the $\mathrm{V}$-shape dislocations. This partial dislocation accounts for the $1.1 \AA$ height difference of the atoms within the V-shape region compared to outside.

In summary, we performed MD simulations of nanoindentation on $\mathrm{NiAl}$ and $\mathrm{Ni}_{3} \mathrm{Al}$ crystals with the (100), (110), and (111) surfaces. Discrete drops in the obtained $P$ - $h$ curves were found to arise from dislocation bursts underneath the indenter. The hardness of the $\mathrm{NiAl}$ and $\mathrm{Ni}_{3} \mathrm{Al}$ system shows significant dependence on the crystallographic planes, specifically the lowest hardness for $\mathrm{NiAl}(100)$ and the greatest value for $\mathrm{Ni}_{3} \mathrm{Al}$ (100). Our MD simulations have revealed that plastic activities are confined near the subsurface region close to the indenter in the case of $\mathrm{Ni}_{3} \mathrm{Al}$ systems while dislocation loops propagate into the substrate in the $\mathrm{NiAl}$ systems.

This research was initially supported by the Defense Threat Reduction Agency (DTRA), Grant No. HDTRA1-081-0036 and has been completed with the support from the Office of Naval Research (ONR), Air Warfare and Weapons Department, grant No. N00014-12-1-0555. Authors would like to thank Dr. Suhithi Peiris and Dr. Clifford Bedford for their encouragement and continued support for this research project. Computations were performed at the University of Southern California High Performance Computing Center using the 560 teraflops Linux cluster and the 4,096-processor Linux cluster at the Collaboratory for Advanced Computing and Simulations.

${ }^{1}$ C. T. Liu and J. O. Stiegler, Science 226(4675), 636-642 (1984).

${ }^{2}$ R. Darolia, J. Mater. Sci. Technol. 10, 157 (1994).

${ }^{3}$ S. C. Deevi and V. K. Sikka, Intermetallics 4(5), 357-375 (1996).

${ }^{4}$ V. K. Sikka, S. C. Deevi, S. Viswanathan, R. W. Swindeman, and M. L. Santella, Intermetallics 8(9-11), 1329-1337 (2000).

${ }^{5}$ E. N. Kablov, B. S. Lomberg, V. P. Buntushkin, E. P. Golubovskii, and S. A. Muboyadzhyan, Met. Sci. Heat Treat. 44(7-8), 284-287 (2002).

${ }^{6}$ R. Maass, L. Meza, B. Gan, S. Tin, and J. R. Greer, Small 8(12), 1869-1875 (2012).

${ }^{7}$ A. G. Fox and M. A. Tabbernor, Acta Metall. Mater. 39(4), 669-678 (1991).

${ }^{8}$ Z. W. Lu, S. H. Wei, and A. Zunger, Acta Metall. Mater. 40(9), 2155-2165 (1992).

${ }^{9}$ H. S. Park, Nano Lett. 6(5), 958-962 (2006).

${ }^{10}$ X. M. Zhang, B. Li, X. W. Sha, Z. Q. Sun, and R. Li, J. Mater. Sci. Technol. 16(4), 370-374 (2000).

${ }^{11}$ W. H. Zhu, D. Fort, I. P. Jones, and R. E. Smallman, Acta Mater. 46(11), 3873-3881 (1998).

${ }^{12}$ E. V. Kozlov, Y. A. Abzaev, Y. V. Solov'eva, V. A. Starenchenko, and N. A. Koneva, Bull. Russ. Acad. Sci.: Phys. 73, 1022 (2009).

${ }^{13}$ Y. J. Wang, G. J. J. Gao, and S. Ogata, Appl. Phys. Lett. 102(4), 041902 (2013).

${ }^{14}$ D. Saraev and R. E. Miller, Modell. Simul. Mater. Sci. Eng. 13(7), 1089-1099 (2005).

${ }^{15}$ C. A. Schuh, J. K. Mason, and A. C. Lund, Nat. Mater. 4(8), 617-621 (2005).

${ }^{16}$ A. H. W. Ngan and P. C. Wo, Philos. Mag. 86(9), 1287-1304 (2006).

${ }^{17}$ Y. L. Chiu and A. H. W. Ngan, Acta Mater. 50(10), 2677-2691 (2002).

${ }^{18}$ W. Wang and K. Lu, J. Mater. Res. 17(9), 2314-2320 (2002).

${ }^{19}$ M. L. Weaver, M. E. Stevenson, and R. C. Bradt, Mater. Sci. Eng., A 345(1-2), 113-117 (2003).

${ }^{20}$ F. Ebrahimi, A. Gomez, and T. G. Hicks, Scr. Mater. 34(2), 337-342 (1996).

${ }^{21}$ X. K. Meng, H. Vehoff, and A. H. W. Ngan, J. Mater. Res. 15(12), 2595-2597 (2000). 
${ }^{22}$ B. Ning, M. E. Stevenson, M. L. Weaver, and R. C. Bradt, Surf. Coat. Technol. 163, 112-117 (2003).

${ }^{23}$ F. W. Herbert, B. Yildiz, and K. J. Van Vliet, "Nanoindentation induced deformation near grain boundaries of corrosion resistant nickel alloys," (Mater. Res. Soc. Symp. Proc., 2011), Vol. 1297, pp. 187-192.

${ }^{24}$ W. Wang, C. B. Jiang, and K. Lu, Acta Mater. 51(20), 6169-6180 (2003).

${ }^{25}$ S. Shim, H. Bei, E. P. George, and G. M. Pharr, Scr. Mater. 59(10), 1095-1098 (2008).

${ }^{26}$ P. C. Wo, L. Zuo, and A. H. W. Ngan, J. Mater. Res. 20(2), 489-495 (2005).

${ }^{27}$ J. Li, K. J. Van Vliet, T. Zhu, S. Yip, and S. Suresh, Nature 418(6895), 307-310 (2002).
${ }^{28}$ P. Walsh, R. K. Kalia, A. Nakano, P. Vashishta, and S. Saini, Appl. Phys. Lett. 77(26), 4332-4334 (2000).

${ }^{29}$ I. Szlufarska, A. Nakano, and P. Vashishta, Science 309(5736), 911-914 (2005).

${ }^{30}$ V. Yamakov, D. Wolf, S. R. Phillpot, A. K. Mukherjee, and H. Gleiter, Nat. Mater. 1(1), 45-48 (2002).

${ }^{31}$ S. P. Chen, D. J. Srolovitz, and A. F. Voter, J. Mater. Res. 4(1), 62-77 (1989).

${ }^{32}$ H. Tsuzuki, P. S. Branicio, and J. P. Rino, Comput. Phys. Commun. 177(6), 518-523 (2007).

${ }^{33}$ J. D. Honeycutt and H. C. Andersen, J. Phys. Chem. 91(19), 4950-4963 (1987).

${ }^{34}$ T. C. Tisone, G. W. Marshall, and J. O. Brittain, J. Appl. Phys. 39(8), 3714-3717 (1968). 